\title{
Minería y Relaciones InTERÉtnicas en Atacama
}

\author{
Héctor Morales ${ }^{1}$ y Rodrigo Azócar²
}

\section{* Introducción}

Resumen

Este trabajo presenta un conflicto denominado "Pampa Colorada", que nos muestra una disputa por el "agua" entre las comunidades atacameñas, las empresas mineras y el Estado. Se analizan, desde una perspectiva conceptual interaccionista, las fricciones propias del conflicto y las diferencias étnicas en juego. Por ello, es clave identificar a los grupos y las diferencias entre ellos. La investigación utiliza una metodología cualitativa con un marcado enfoque etnográfico, desarrollado en las comunidades de Socaire, Peine, Toconao y San Pedro de Atacama.

Palabras claves: minería - sistema interétnico - agua - atacameños.

Abstract

This paper presents a conflict called "Pampa Colorada" which shows a dispute over the "water" between the Atacama communities, mining companies and the state. It is analyzed from a conceptual perspective Interactionist the friction of conflict and ethnic differences at stake. It is therefore essential to identify the groups and the differences between them. The research uses a qualitative methodology with a strong ethnographic approach developed in the communities of Socaire, Peine, Toconao and San Pedro de Atacama.

Key words: mining - ethnic system - water - Atacameños.

1 Departamento de Antropología, Facultad de Ciencias Sociales, Universidad de Chile. Ignacio Carrera Pinto 1045, Ñuñoa, Santiago, CHILE. Email: hmorales@u.uchile.cl

2 Proyecto de Trayectorias de Patrimonialización. Departamento de Antropología, Facultad de Ciencias Sociales, Universidad de Chile. Ignacio Carrera Pinto 1045, Ñuñoa, Santiago, CHILE. Email: rodrigo.azocar.d@gmail.com reiteradas ocasiones, se han enfrentado con las comunidades indígenas andinas para desarrollar su actividad productiva en el norte de Chile, disputándose sobre todo el agua, y generando grandes efectos negativos sobre estas últimas.

En tiempos contemporáneos podemos mencionar, al menos, seis casos de impacto negativo en estas comunidades. Primero, la desaparición de la laguna Ojos de San Pedro en la década de 1960 a causa del mineral de Chuquicamata, y también del Ferrocarril de Antofagasta a Bolivia (FCAB) y una azufrera, que influyó directamente en la desaparición del poblado quechua estación San Pedro que estaba a su alrededor. Segundo, la apropiación de las aguas de la comunidad de Toconce por parte de Empresa de Servicios Sanitarios de Antofagasta (ESSAN) para el abastecimiento de agua potable a centros urbanos y mineros. Tercero, la contaminación de las aguas del Loa en 1997 y 2000 con sustancias de relaves mineros de Chuquicamata, que llevó a una crisis ambiental, económica y social a la comunidad aymara de Quillagua, en donde muchos comuneros enajenaron sus derechos a SQM, pues su utilización tanto para consumo como para la agricultura era imposible. Por lo demás, el 2007 se comprobó que SQM hacía extracciones ilegales de agua, lo que no permitía que llegase agua al pueblo. Cuarto, el uso de aguas subterráneas por parte de la Compañía Minera Cerro Colorado S.A., filial de BHP Billiton, que ha derivado en el desecamiento de vegas y bofedales de Pampa Lagunillas, afectando directamente a la comunidad aymara de Cancosa, quien ha hecho un uso ancestral del territorio. Quinto, el año 2000, a 
petición de la comunidad atacameña de Chiu-Chiu, la Dirección General de Aguas (DGA) declara saturada la cuenca hidrográfica del Loa, prohibiéndose la obtención de derechos de agua superficiales sobre este recurso hídrico, el principal de la región y cuyo curso es utilizado por CODELCO (Corporación Nacional del Cobre) en un $30 \%$ aproximadamente (Molina 20063). Por esta sobreexplotación de aguas del Loa, la comunidad aymara de Quillagua se vio directamente afectada por el solo hecho de posicionarse en el curso inferior del río, en donde casi ya no llegan las aguas. Igualmente se han visto afectadas a causa de la explotación indiscriminada, y la contaminación del río Loa y sus afluentes, las comunidades atacameñas de Conchi Viejo, Pueblo de San Pedro, el mismo Chiu-Chiu, Lasana, Ayquina, Toconce y Caspana. Y sexto, el impacto negativo de Minera Escondida Limitada (MEL) sobre el salar de Punta Negra a causa de la extracción de aguas, lo que ha bajado los niveles lagunares del salar, alterando directamente la forma de vida de los flamencos que anidaban allí (DGA 2000; Rivera 2005-2006; Barros 2008; Yáñez y Molina 2008, 2011; Madaleno 2009).

Todos estos conflictos se han dado en el marco de una condición objetiva en el norte de Chile, la escasez del agua, la cual se debe a las escasas precipitaciones, los altos índices de evaporación, los largos períodos de sequía (hablamos del desierto más árido del mundo), el calentamiento global y las cantidades industriales de extracciones de agua para fines mineros, las cuales se prevé que irán en aumento en el futuro. Esto ha hecho que el balance hídrico de la Región de Antofagasta sea negativo, abundando las áreas de protección y restricción del uso del agua, así como las áreas en que el recurso se ha declarado agotado, como ocurre por ejemplo en la Región de Antofagasta, en donde el año 2000 se declara agotada la cuenca hidrográfica del Loa; esto deriva, finalmente, en la prohibición de otorgamiento de derechos de agua superficiales de esta cuenca hídrica, lo que hace que hoy en día todas las disputas de agua de la región se hagan solo sobre derechos de aguas subterráneas (DGA 2000). Frente a esta escasez hay un desierto históricamente colmado de minerales que requieren del agua para su explotación por parte de las empresas mi-

3 El 29,5\% del agua del Loa es utilizado por la minería, un 34,3\% para la agricultura, y un $36,2 \%$ para agua potable. neras, no obstante, ya no parece ser un fenómeno simple la extracción industrial del agua, pues los pueblos indígenas del norte de Chile se encuentran emplazados precisamente en las zonas de altura y fuentes de este recurso y cada día logran empoderarse más sobre sus territorios.

Por estas razones, este artículo pretende explicar los sistemas interétnicos en juego en el norte del país entre la minería, las comunidades atacameñas y el Estado chileno, visto a la luz del conflicto de Pampa Colorada del año 2007.

La hipótesis de este trabajo es que los conflictos entre comunidades indígenas y minería emergen de las fricciones y relaciones sociales interétnicas en contextos multiculturales. La metodología utilizada es eminentemente cualitativa y apunta a identificar actores sociales y conflictos con alcances socio y etno ambientales en la zona del salar del desierto de Atacama en el norte andino de Chile. Esta investigación se inició - dentro del marco de un proyecto VID N ${ }^{\circ} 6 / 2013$ de la Universidad de Chile - con una revisión bibliográfica y de archivo que permitió el examen de expedientes judiciales y gubernamentales sobre conflictos etnoambientales en la Segunda Región, esto se complementó con datos etnográficos de líderes y comuneros (2013-2014), ello permitió generar tipologías y escenarios relevantes dentro del conflicto y las relaciones de poder entre los diversos grupos sociales en Atacama.

\section{PERSPECTIVA DE LA ETNICIDAD COMO RELA- CIÓN SOCIAL}

El paradigma interaccionista propone una forma de organización cambiante, transitoria y contextual (al contrario del primordialismo, el instrumentalismo y el constructivismo), orientada a regular la interacción social a través de la organización de la diferencia y la adscripción/autoadscripción, por lo que las identificaciones étnicas resultantes no se vinculan necesariamente a un patrimonio cultural exclusivo. La categoría frontera o límite aparece así como un rasgo fundamental de lo étnico, ya que la misma existencia del grupo depende de la pertinencia de sus límites.

Se suele identificar a E. Shils (1957) como el primero en 
sugerir la noción de primordialismo para fundamentar su propuesta acerca de la importancia de los grupos primarios en la configuración de las sociedades complejas. La etnia es un grupo de parentesco ampliado; no importa que sea real o ficticio, lo que le confiere la fuerza coercitiva es un deber moral para con "los suyos" y una fuerza emocional que despierta el simbolismo de los vínculos de sangre y de familia (Isaacs 1975). Por otra parte, las teorías constructivistas acentúan el carácter elaborado de las identidades de los grupos étnicos, en cuya constitución se evidencian componentes históricos, lingüísticos, culturales e imaginarios. La idea de construcción social, en la línea de análisis de P. Berger y T. Luckmann (1973), constituye un enfoque particularmente útil para el estudio de procesos de etnogénesis y de etnificación tanto históricos como contemporáneos (Roosens 1989). Esta perspectiva se nutre de formulaciones teóricas referidas a la formación de naciones a partir de la "invención de la tradición" de E. Hobsbawm (2002) o de las "comunidades imaginadas" de B. Anderson (1993). Otra perspectiva teórica ligada al constructivismo es la instrumentalista, tendencia en cierto modo predominante a partir de las propuestas de A. Cohen (1974), y de N. Glazer y D. Moyniham (1975). Para los instrumentalistas, la identidad étnica es básicamente un recurso para la movilización política, la cual es manipulada para obtener determinados fines. Glazer y Moyniham fueron de los primeros en señalar que un grupo étnico funciona precisamente como un grupo de interés.

Ahora bien, el enfoque generativo o interaccionista, acuñado por Fredrik Barth (1976) y ampliamente difundido por su carácter dinámico e interactivo, disocia al grupo étnico de la tradicional relación con una cultura específica. Las identidades se construyen para contrastarse de manera tal que:

1) Los grupos étnicos deben considerarse una forma de organización: la organización social de las diferencias culturales. Esto quiere decir que hacia adentro y hacia fuera del grupo, las relaciones sociales se organizan a partir de diferencias culturales. 2) Tales diferencias culturales no se suponen objetivas; están subjetivamente definidas y seleccionadas como significativas por los actores sociales. De esa manera se clasifican a sí mismas y a la vez son clasificados por otros con fines de interacción. En efecto, "los rasgos que son tomados en cuenta no son la suma de diferencias objetivas, sino solamente aquellos que los actores mismos consideran significativos" (Barth 1976: 15).

De aquí la importancia central de la autoadscripción y de la heteroadscripción categorial en la teoría de Barth. 3) La identidad étnica se construye o se transforma en la interacción de los grupos sociales mediante procesos de inclusión-exclusión, los cuales establecen fronteras entre dichos grupos, definiendo quiénes pertenecen o no a los mismos. 4) La identidad de los grupos étnicos se define por la continuidad de sus fronteras, a través de procesos de interacción interétnica, no por las diferencias culturales que, en un momento determinado, marcan o definen tales fronteras. $\mathrm{O}$, dicho en otros términos, pueden variar los "emblemas de contraste de un grupo" (De Vos et al. 1982: 13) sin que se altere su identidad. De lo contrario, sostiene Barth, no se podría explicar la continuidad en el tiempo de la entidad. En efecto, "gran parte del contenido cultural que en un momento determinado es asociado con una comunidad étnica no está restringido por estos límites; puede variar, puede ser aprendido y modificarse sin guardar ninguna relación crítica con la conservación de los límites del grupo étnico" (Barth op. cit.: 49).

Si bien las categorías étnicas presuponen diferencias y marcadores culturales, no se puede suponer una simple relación de equivalencia entre las unidades étnicas basada exclusivamente en la observación de similitudes o diferencias culturales. Los rasgos que son tomados en cuenta por un determinado grupo étnico, a modo de marcadores centrales de diferenciación, no se corresponden con la suma de las diferencias objetivas, sino particularmente con aquellos que los actores mismos consideran significativos. Algunos rasgos culturales son utilizados por los actores como emblemas de diferencia o marcadores culturales. Otros son pasados por alto, y en algunas relaciones hay diferencias radicales que son desdeñadas.

El aporte del enfoque étnico a partir de Barth supone que, a pesar de compartir marcadores, los grupos establecen relaciones de distinta jerarquía o importancia con cada uno de ellos. Por lo tanto, en vez de hacer desaparecer las diferencias culturales que existen entre ellos, los mismos marcadores pueden hacer que se refuercen. 
Ciertos elementos culturales ejercen como marcadores de diferencia. Su importancia aparente va cambiando conforme se modifican las relaciones del grupo cultural al que pertenecen y el contexto en que dichas relaciones se dan. El grupo - tal y como se reconoce- existe por su contraste con el otro, contraste que se expresa por medio de los marcadores culturales: organización, religión, lengua, territorio, entre otros.

La presente investigación, con los conceptos aquí expuestos, examinará la pertinencia de la perspectiva relacional para el caso de la emergencia de la etnia atacameña, en cuanto contexto y vínculos sociales que generan las organizaciones sociales a partir de la diferencia, la autoadscripción, la adscripción y continuidad de sus fronteras a través de procesos de interacción interétnica con el Estado y empresas privadas.

Lo atacameño, bajo esta perspectiva interaccionista, será entendida como cambiante, transitoria y contextual; una interacción social de la diferencia, regulada por la adscripción colla, quechua, boliviano o runaco y la autoadscripción atacameña frente a otros actores relevantes como el Estado chileno y las empresas privadas (Morales 2013).

\section{Fricciones interétnicas}

Las fricciones son los conflictos contingentes y las fisuras son conflictos históricos de larga data, en Atacama existen muchas relaciones sociales pactadas y otras conflictivas. La pregunta es qué hecho convierte estas relaciones sociales en étnicas, será la presencia de marcadores culturales como la lengua, organización, territorio o religión, lo que determinará las fronteras. Entonces, las fricciones son situaciones conflictivas que emanan de la lucha por imponer distinciones específicas sobre los marcadores culturales en juego.

Describir fricción en Atacama nos permite caracterizar los contornos culturales, tanto de los atacameños como de los grupos involucrados. Éstas pueden ser pesquisadas en las disputas, por ejemplo, entre comunidades indígenas y empresas mineras; ambas compiten por el "agua" puesto que éste es un recurso esencial, tanto para las comunidades, como para la actividad industrial minera. “...las causas a estos problemas las encontramos, en gran medida, en la enorme cantidad de agua que extraen las faenas mineras (...) dejando de lado a la actividad ancestral de los atacameños" (I Congreso Atacameño 1998: 17).

Esta situación de conflicto por el "agua" genera una nueva fricción frente al Estado, a causa del estilo de desarrollo económico llevado a cabo por los gobiernos de la Concertación, que evalúa y mide las inversiones de los grandes proyectos mineros y turísticos solo considerando indicadores de tipo económico de costo beneficio, en desmedro de los pueblos indígenas. En este caso, es a través del recurso hídrico que los actores se construyen a sí mismos en relación a otros por distintos usos y valoraciones del agua.

A partir de la Ley Indígena (1993) "lo atacameño" se muestra hacia fuera como la adscripción que da unidad a todos los pobladores de Atacama. Pero hacia adentro, se reconoce que solo los pobladores de San Pedro de Atacama serían los atacameños, y se agregan dos grupos importantes, los collas y quechuas; ambas denominaciones son rotuladas por los atacameños de San Pedro de Atacama. Estos últimos negarán estos apelativos y se autoadscribirán a los gentilicios derivados del nombre de sus pueblos de residencia (Morales 2010).

"Lo atacameño" es una forma de organización, la organización social de las diferencias con su entorno nacional y transnacional. Tales diferencias no son solo aspectos de color de piel, vestimenta o formas de hablar; están subjetivamente definidas y seleccionadas como significativas por los actores sociales, quienes se clasifican a sí mismos, y a la vez, son clasificados por otros con fines de interacción.

La etnicidad atacameña se construye o se transforma en la interacción con los grupos sociales mediante procesos de inclusión-exclusión. Aquí se establecen los parámetros de integración atacameña.

\section{Sistema interétnico}

Es Cardoso de Oliveira (2007) quien acuña el concepto de "sistema interétnico", tomando en cuenta la concepción cultural de Barth. En este sentido, la esencia de la identidad étnica es la identidad contrastante, la cual 
implica la afirmación del nosotros frente a los otros, es una toma de posición. Cuando un grupo o una persona se autodefine, lo hace como medio de diferenciación en relación a algún otro grupo o persona a las cuales se enfrentan. Por tanto, se trata de una identidad que surge por oposición, que no puede ser afirmada en aislamiento. $Y$ en el caso de la identidad étnica, ésta se afirma negando la otra identidad, la cual ha sido visualizada de manera etnocéntrica (en base a valores y una ideología). En otras palabras, la identidad étnica se define por una situación de contacto interétnico y sobre todo cuando éste se da como fricción interétnica (ibíd.).

Sobre esta base es que Cardoso de Oliveira construye su matriz de los sistemas interétnicos, la cual se basa en situaciones de contacto con sus respectivas culturas de contacto, como detallaremos a continuación (Tabla 1): timos poseen gran poder de determinación sobre la dinámica del sistema interétnico, gracias a su mayor poderío bélico y económico, lo que constituye un sistema asimétrico.

Es precisamente en este tipo de sistema que se genera la fricción interétnica, siendo la base del sistema interétnico la conjunción de intereses económicos contradictorios, pues, por un lado, los indios pretenden obtener bienes manufacturados, y por otro, el blanco procura hacerse del territorio o de la mano de obra indígena. Esta situación se generó por la expansión de la sociedad nacional, pasando a convertirse los bienes extranjeros en indispensables para los indios, creando una dependencia definitiva de éstos hacia la sociedad nacional. La sociedad nacional incluye en sus planes de expansión o desarrollo al indio y a su

Tabla 1. Matriz de los sistemas interétnicos.

\begin{tabular}{|l|l|l|}
\hline & \multicolumn{1}{|c|}{ Intertribales } & \multicolumn{1}{c|}{ Interétnicos } \\
\hline Simetría & Relaciones igualitarias & Relaciones igualitarias \\
\hline Asimetría & Relaciones jerárquicas & Relaciones de sujeción-dominación \\
\hline
\end{tabular}

Fuente: Cardoso de Oliveira 2007.

1) Primero, tenemos un sistema intertribal simétrico que da origen a relaciones igualitarias, el cual es probablemente una figura teórica en la medida en que progresivamente van escaseando las relaciones tribales de orden simétrico.

2) Segundo, un sistema intertribal asimétrico donde emergen relaciones jerárquicas, el cual corresponde al surgimiento de sistemas estratificados, y por lo tanto, de estatus (como los contextos migratorios entre pueblos indígenas).

3) Tercero, un sistema interétnico asimétrico que da nacimiento a relaciones de sujeción y dominación, lo cual ocurre en áreas de fricción interétnica, como la relación entre blancos e indios en contextos coloniales o de colonialismo interno. La naturaleza de la relación entre blancos e indios es de dominación y sujeción, lo que denota un tipo de colonialismo interno. En otras palabras, esta situación se da cuando entran en contacto grupos tribales y segmentos regionales de la sociedad nacional, donde estos úl- territorio, y en el momento en que la mano de obra indígena y sus territorios se valorizan, el indio ya no tiene escapatoria, queda subyugado y su territorio es conquistado. El indio queda, de esta forma, doblemente subyugado: por un lado, vive una sujeción étnica, con todas las implicancias de la fricción interétnica; y por otro, una sujeción interregional, en que una región subdesarrollada queda sometida a una desarrollada, de la cual emigran capitales, organizaciones empresariales $y$, muchas veces, las decisiones sobre el destino de las poblaciones locales, indígenas o no, son tomadas desde las zonas desarrolladas hacia las subdesarrolladas.

4) Y cuarto, un sistema interétnico simétrico con relaciones igualitarias, un tipo de sistema que pareciera ser solo una posibilidad teórica, no existiendo evidencia empírica de su presencia, pues se trataría de un sistema interétnico compuesto por indios y blancos con relaciones simétricas. Este tipo de sistema no se presenta en la práctica pero sí existe una ideología igualitaria, sobre todo en los centros metropolitanos 
de la sociedad nacional, precisamente los que menos tienen contacto con los grupos indígenas (ibid.).

\section{DE LA FRICCIÓN INTERÉTNICA POR EL AGUA ENTRE LA MINERÍA Y LAS COMUNIDADES ATA- CAMEÑAS AL SISTEMA INTERÉTNICO}

A continuación, explicaremos brevemente un conflicto denominado Pampa Colorada que ocurrió hace unos años en Atacama, el cual utilizaremos como ejemplo de las fricciones y relaciones interétnicas entre la minería y las comunidades indígenas.

Pampa Colorada fue un conflicto etnoambiental (Folchi 2009; Larraín 2010; Skewes, Rehbein y Mancilla 2012) que se produjo en la comuna de San Pedro de Atacama en el año 2007, a causa de que Minera Escondida Limitada (MEL) tenía un proyecto del mismo nombre en la zona que buscaba extraer aguas subterráneas de las cuencas altoandinas de la comuna, por sobre los $4000 \mathrm{msnm}$ y muy cerca de la frontera con Argentina ${ }^{4}$. Este proyecto minero, en estrictos términos, pretendía extraer 1027 litros por segundo durante 20 años. Si a esto le agregamos los 60 años de efectos posteriores, según el Estudio de Impacto Ambiental de la minera (EIA), completamos un total de 80 años de impacto de este proyecto minero, es decir, hablamos de cantidades industriales de agua en una zona en que este recurso es escaso. El costo de la explotación de estas aguas subterráneas sería de USD 300 millones, en el cual se tenía contemplada la construcción de un sistema de tuberías de $190 \mathrm{~km}$ de extensión, desde la Cordillera hasta las faenas de la mina, el cual pasaría por al menos 54 sitios arqueológicos. De este modo, MEL pretendía utilizar agua dulce en sus procesos productivos, siendo esa posibilidad más barata que la desalinización de agua marina, la cual valía, por aquellos años, unas cinco veces más.

4 Recordemos que los derechos sobre aguas superficiales de la cuenca hidrográfica del río Loa fueron declaradas agotadas por la DGA el año 2000 , disputándose desde esa fecha en adelante los derechos sobre fuentes de aguas subterráneas en la Región de Antofagasta.

5 Desde la década del 9o, el agua de Pampa Colorada fue demarcada y reclamada como propias por la Comunidad Atacameña de Socaire.
Fue el 2005 cuando Exploraciones Mundo S.A. (EMSA) llega a la comunidad atacameña de Socaire ${ }^{5}$ pidiendo autorización para realizar un estudio sobre el agua en Pampa Colorada a cambio de una compensación económica, lo cual derivó en las inscripciones de los derechos de este recurso, situación que es vista como un error por parte de la comunidad, quienes no recayeron en las segundas intenciones de la empresa. Un dirigente socaireño comenta: "En Exploraciones Mundo cometimos nosotros el error, ahí negociamos... Exploraciones Mundo exploró en todas partes, pero al final querían vender agua a Escondida" (dirigente de la comunidad de Socaire, 2013).

Tal como comenta el comunero, el 2007 EMSA quería vender tales derechos a MEL para explotar el agua con fines industriales mineros. De inmediato se generó una división interna al interior de la comunidad de Socaire entre quienes querían ceder el agua y quienes no: entre los primeros se argumentaba, influidos por las informaciones de MEL, que las aguas que se extraerían desembocaban en Argentina, por lo que no habría efectos sobre la zona, o que se trataba de agua salada y no dulce. En general, opinaba de esta manera la gente joven del pueblo, quienes veían una oportunidad de crecimiento en el acercamiento de esta industria minera, ya sea en términos económicos, académicos, sociales, etc. Una comunera afirma: "Yo sí quería que sacaran el agua. Porque de repente si entraban esos 20 millones y la gente sabe trabajar va a levantarse el pueblo... Entonces mi esposo decía que no estaban arruinando acá porque era agua salada, eran aguas que venían de salares que vienen de allá. Va para Argentina decía él. Para allá podía arruinar, pero no para acá para Chile" (comunera de Socaire, 2013).

Por otra parte, quienes se oponían temían que se secara el agua del pueblo o las fuentes acuíferas circundantes (como las lagunas Miscanti y Meñique, Tuyajto, o Aguas Calientes), forzando la migración, o por el desecamiento de bofedales, bajo el supuesto de que todas estas fuentes de agua estaban conectadas subterráneamente. Una dirigente de Socaire dice:

"Para mí no era bueno vender el agua, quizás en ese tiempo íbamos a estar bien pero después con el tiempo se iba a ir secando el agua y tendríamos que migrar y a dónde nosotros nos vamos si 
estamos aquí arraigados, somos indígenas y somos criados acá y sabemos cómo vivir acá. En otro lado no vamos a hacer lo mismo que acá... No tendríamos dónde ir, tenemos hijos por delante, nietos por delante... El que sabe trabajar en la tierra quizás va a sobrevivir, el que sabe agricultura, el que sabe ganadería sabe sobrevivir siempre, pero no la plata, porque la plata quizás va a ser un rato pero después ya no va a haber" (dirigenta de la comunidad de Socaire, 2013).

Cuando las comunidades del salar de Atacama se enteraron del proyecto, de inmediato se generó una alerta en ellas, pues se temía por el libre escurrir de las aguas desde las zonas altas a las bajas. Un dirigente de San Pedro de Atacama dice: "Por una cuestión lógica del mundo andino, si uno pincha aguas arriba, la lógica andina es que luego los niveles, las aguas, digamos, que escurren hacia abajo van a verse totalmente afectadas" (dirigente de la comunidad de San Pedro de Atacama, 2014).

Es así que las comunidades de Peine, Toconao y San Pedro de Atacama presionan a Socaire para que rechace el proyecto y la presencia de la minera en sus territorios. Tal situación se logra, quienes se oponían al proyecto logran convencer a quienes querían su aprobación, y es así que estas cuatro comunidades atacameñas aúnan esfuerzos para enfrentarse a esta empresa transnacional, sumando las fuerzas del Consejo de Pueblos Atacameños (suprainstitución que reúne a todas las comunidades indígenas de la zona "Atacama La Grande", en ese entonces también agrupaba a la zona del "Alto Loa"), el municipio de San Pedro y la asesoría de algunas organizaciones legales y medioambientales. De acuerdo a una dirigente de Peine, la solidaridad del pueblo atacameño se alcanzó por el siguiente motivo: "Fueron las reuniones del Consejo que generaron este ambiente, pero había esta sensación de hermandad, de apoyo" (dirigenta de la comunidad de Peine, 2013).

Desde entonces, todos juntos comenzaron a reactivar un movimiento social para generar revuelo y sensibilidad en las instituciones estatales atingentes que deliberarían en la COREMA (Comisión Regional del Medio Ambiente) de Antofagasta la viabilidad del proyecto, específicamente por medio del SEIA (Sistema de Evaluación de Impacto Ambiental). Es así como las comunidades organizan la protesta, haciendo visible su postura de rechazo al proyecto a través de banderas negras como señal de descontento y oposición en los diferentes pueblos, marchas, declaraciones públicas, jornadas de contrainformación a la minera, mensajes radiales en contra del proyecto y la consecución de asesoramiento legal y medioambiental, además de una relativa visibilización del conflicto por medio de la prensa (televisión, radio y periódicos). Un dirigente de Toconao afirma: "Hubo movimiento, algunas protestas por acá y por allá, el descontrol en las comunidades, las observaciones de las comunidades, las banderas negras. Salimos en entrevistas también, en ediciones cortitas, pero salimos en entrevistas... La Radio Toconao sirvió también para difundir problemas, se juntaron muchas pequeñas cosas como para hacerles frente" (dirigente de la comunidad de Toconao, 2014).

A su vez, un dirigente de Socaire dice en torno a las movilizaciones: "Las casas las teníamos con banderas negras... Fuimos a Antofagasta, a la Dirección de Aguas a hacer una marcha ahí, una protesta, en la plaza y todo eso en Antofagasta. Nos pusimos de acuerdo con Toconao y Peine y nos fuimos" (dirigente de la comunidad de Socaire, 2013).

A la postre, la movilización de las comunidades fue esencial para frenar las intenciones de MEL en sus territorios, pues finalmente, el proyecto de Pampa Colorada fue rechazado en octubre de 2007 casi de forma inédita por el Estado chileno ${ }^{6}$, específicamente, por las instituciones sectoriales que lo representan a través del SEIA y de la COREMA de Antofagasta, quien calificó desfavorablemente el proyecto porque vulneraba las letras b), e) y f) del artículo 11 de la ley 19.300 sobre Bases Generales del Medio Ambiente, vale decir, de acuerdo a esta institución estatal se afectaba la cantidad y calidad de recursos naturales (en este caso el agua), se alteraba significativamente el valor paisajístico o turístico de la zona y se vulneraban sitios con valor antropológico, arqueológico y/o histórico; en el fondo, se alteraba el patrimonio cultural (Yáñez y Molina 2008, 2011; Larraín et al. 2010).

6 Afirmamos tal situación porque en Chile, por más oposición que generen los proyectos de inversión, igualmente son aprobados. Las cifras son claras: entre 1997 y el 2006 , de un total de 471 proyectos de inversión de empresas nacionales y transnacionales, solo un 7\% fue rechazado (Mc Phee 2010). 


\section{El valor del agua para las comunidades atacame- ñas}

Debemos comenzar diciendo que el agua para el pueblo atacameño nunca ha sido un recurso de fácil acceso, e históricamente se ha obtenido y distribuido por trabajo comunitario. Esta situación se debe a la localización territorial de este pueblo indígena, el cual se encuentra emplazado en el desierto de Atacama, donde las fuentes hídricas son escasas. Pero también ha influido el abandono histórico que han sufrido estas poblaciones por parte del Estado, quienes durante décadas carecieron de servicios básicos como el agua potable, la electricidad y el alcantarillado, cuestiones que se han logrado conseguir solamente en las últimas décadas gracias a las reivindicaciones étnicas, la Ley Indígena, y la importancia que ha adquirido San Pedro de Atacama y sus alrededores como destino turístico y fuente minera.

Ahora bien, las comunidades atacameñas requieren del agua para desarrollar su forma de vida y cultura. En estos términos, podríamos decir que este recurso tiene al menos tres dimensiones: primero, es un recurso indispensable para el desarrollo de la cultura andina de este pueblo, a través del desarrollo de sus dos principales actividades económicas, como son la agricultura y el pastoreo; segundo, el agua también tiene una connotación simbólica en la cosmovisión andina, puesto que se vincula a los cerros al producirse allí las lluvias y nieves, siendo estas cumbres deidades de la naturaleza que permiten mediante agua y pastos la reproducción económica de las comunidades; y tercero, el agua también es un recurso que cohesiona, fortalece, revitaliza y reivindica la organización social, política y cultural de las comunidades atacameñas (como sucede con los turnos de agua y las limpias de canales, por ejemplo), pues la escasez de este recurso ha generado que, históricamente, las comunidades se organicen para su acceso y distribución ${ }^{7}$, especialmente en las zonas altoandinas semiáridas. Todo esto ha llevado a algunos autores a aseverar que estos pueblos tienen una "cultura hídrica". De esta forma, vemos que el agua no es solo un recurso natural para las comunidades atacameñas, sino que igualmente social y cultural (Castro et al. 1990; Castro et al. 1994; Gentes 2004; Molina 2006; Valenzuela 2006).

Relacionando estas tres dimensiones del agua, podemos decir que los cerros son las divinidades tutelares de las comunidades andinas, y por supuesto las atacameñas, ya que en el contexto del desierto de Atacama, el agua es escasa y se produce precisamente en las zonas de altura, es decir, en los imponentes cerros que rodean a las comunidades, en forma de agua y nieve, bajando a través de pequeños ríos o aflorando subterráneamente, otorgando el agua tanto para la agricultura como para el pastoreo de animales. Pese a esta benigna situación, el agua igualmente sigue siendo escasa, por lo que las comunidades históricamente se han organizado para acceder de forma igualitaria y comunitaria al acceso de este recurso, volviéndose por tanto un elemento vital en cuanto a la subsistencia en el desierto, teniendo diferentes carices, económico, social, político y cultural, los cuales siempre se expresan de manera conjunta, son inseparables, adquieren un sentido holístico.

Es por todas estas razones que al interior de las comunidades atacameñas se generó consenso de oposición a la venta del agua a la minería, pues se trata de un recurso vital para el pueblo ${ }^{8}$, además de un importante eje de conflicto y de lucha política histórica. Por lo demás, en las comunidades andinas hay un historial de experiencias negativas en sus relaciones con la minería, pues al

7 Mostny (1954) ya hablaba de la escasez de agua en Peine en 1949, que dificultaba incluso el riego de cultivos, en una época en que aún la megaminería no marcaba presencia en la comuna de San Pedro de Atacama, cuya escasez se ha acentuado hasta niveles críticos con la aparición de esta actividad. Esta autora incluso dice que se hacían misas y se llevaban las imágenes de la iglesia en procesión a las afueras del pueblo en aquella época para que lloviera y se terminaran los extensos períodos de sequía.

8 Para reflejar la importancia del agua para el pueblo atacameño, daremos el ejemplo de Socaire, comunidad que le da variados usos a este recurso. Primero, para la agricultura, mecanismo que funciona a través de los turnos de agua; segundo, para el pastoreo, pues la presencia de agua se asocia de inmediato a los animales, quienes se alimentan de los pastos de vegas y bofedales, los cuales dependen a su vez de las lluvias y nieves que caigan durante el año, así como del equilibrio del balance hídrico, lo que les permite obtener carne, abono y lana para desarrollar la artesanía y el turismo; tercero, para el consumo humano y las tareas cotidianas del hogar; cuarto, el uso de una turbina hidráulica que le permite obtener electricidad propia al pueblo; y quinto, el significado ceremonial que adquiere el agua en Socaire, lo cual se ve claramente reflejado en la Fiesta de Limpia de Canales, que se realiza hacia fines de octubre. 
menos han sido víctimas de los siguientes menoscabos: la pérdida de derechos sobre aguas ancestrales, extinción de fuentes de agua, daño ecológico a las tierras ancestrales, pleitos locales por el acceso y uso de recursos naturales, despoblamiento de pueblos tradicionales y migración a centros urbanos y mineros, reducción de la agricultura y el pastoreo, y contaminación de terrenos y cursos de agua (Gentes 2004; Madaleno 2009). De esta manera, las distintas comunidades indígenas se autoidentifican como atacameñas en cuanto organización social para enfrentarse a las empresas mineras, es decir, a través del agua se construyen a sí mismas y emerge su identidad común y solidaridad.

\section{El valor del agua para la minería}

MEL es una empresa transnacional de capitales angloaustralianos ${ }^{9}$ que funciona en Chile desde 1991. Esta minera está emplazada a $170 \mathrm{~km}$ al sureste de Antofagasta y a $3100 \mathrm{msnm}$. Actualmente, MEL es la operación minera de cobre individual de mayor producción global, pues produjo el 6,3\% del cobre mundial el año 2012, aportando con 1.075 .825 toneladas métricas de cobre $^{10}$ y obteniendo utilidades por más de USD 3.000 millones. El 2007, el año del conflicto de Pampa Colo-

9 Gracias a la adopción del modelo neoliberal durante la dictadura militar en Chile, hoy en día el 65\% de la industria del cobre es privada y solo el $35 \%$ es estatal. Se decidió, por aquellos años, abrir la explotación de este mineral a empresas privadas nacionales y extranjeras para acelerar la producción, argumentando la magnitud de los recursos, la cual en pocos años podía verse devaluada a nivel global. En otras palabras, ante el riesgo de la obsolescencia del cobre, había que expandir su explotación hasta agotarlo si fuera necesario, de manera tal de obtener la mayor renta posible en poco tiempo y a un buen precio internacional de la materia prima, cuestión que se veía imposible si el Estado actuaba en solitario, lo que generó la abertura del mercado (Folchi 2003, 2009). Esta decisión ha ido en directo perjuicio del agua, pues mayor producción de cobre significa mayor consumo de este recurso natural, como lo iremos viendo en este apartado.

10 Lo que corresponde al 19,8\% del cobre producido en el país y al $36,6 \%$ del producido en la Región de Antofagasta (COCHILCO 2013b).

11 Estos datos fueron obtenidos en base a Minera Escondida (2013) y COCHILCO (2013a), puesto que ambos reportes corresponden al mismo año y MEL participa de la encuesta de COCHILCO, la cual entrega cifras nacionales y regionales. rada, MEL representó el 9,26\% del cobre producido en el mundo, a través de 1.483.934 toneladas y generando utilidades por más de USD 6.000 millones (Minera Escondida 2008 y 2013).

La minería del cobre, en general, utiliza el recurso hídrico a lo largo de todo su proceso productivo, tales como el área mina, área planta, relaves y campamentos y servicios, convirtiéndose en un insumo estratégico e imprescindible para esta actividad económica. El origen de esta materia prima de uso minero, a esta altura, proviene de aguas superficiales, subterráneas, provenientes del mar y adquirida a terceros. Con respecto a MEL, el 98\% del agua consumida se utiliza en la faena misma, empresa minera que consume el 16,7\% de las aguas destinadas a la minería del cobre de la Región de Antofagasta, la zona más minera del país (que consume el 40\% del agua utilizada en la minería del cobre en Chile), es decir, utiliza $2,07 \mathrm{~m} 3 / \mathrm{s}$ de agua ${ }^{11}$. Y precisamente, el $41 \%$ de las aguas utilizadas por la industria del cobre en la Región de Antofagasta son de origen subterráneo a su vez ${ }^{12}$, tal cual se pretendía en Pampa Colorada. En particular MEL, al año 2007 , año del conflicto, el $71,55 \%$ de las aguas consumidas por la empresa fueron de origen subterráneo, mientras que el 2012 lo fue el $75,64 \%{ }^{13}$.

Todo esto ocurre en un contexto en que Chile tiene la mayor producción ${ }^{14}$ y cantidad de reservas de cobre a nivel mundial, frente a un aumento progresivo de la demanda global de este mineral en las últimas décadas.

12 Un 33\% de índole superficial, un 9\% de adquiridas a terceros y un $18 \%$ de agua de mar. Con respecto a esto mismo, y para ser justos, también es necesario mencionar que es en esta región donde se utiliza la mayor tasa de aguas marinas, la alternativa más factible a futuro para la minería, pues reduce la presión sobre otras fuentes acuíferas y aumenta la disponibilidad del recurso, aunque con grandes costos energéticos a causa de la altitud de las minas, lo cual dificulta el bombeo de las aguas desde el mar (COCHILCO 2013a). En específico, MEL tiene una planta desalinizadora que logra producir $525 \mathrm{l} / \mathrm{s}$, proyecto que actualmente se está ampliando con una inversión de USD $3.500 \mathrm{mi}-$ llones y cuyo funcionamiento se estipula para el 2017 (Minera Escondida 2013; La Tercera 2013).

13 El 2007, esta empresa consumió en su totalidad 95.796.023 m3 de agua, mientras que el 2012 fueron 65.262.699 m3 (Minera Escondida 2008 y 2013).

14 En el país se produce el 31,8\% del cobre mundial (COCHILCO 2013b). 
Sin embargo, pese a estas ventajas el negocio del cobre debe enfrentar un escenario nacional de crisis hídrica, a causa del aumento de las temperaturas, la evaporación, las sequías, bajas precipitaciones y nieves en la zona norte y central del país. En la Región de Antofagasta, la situación del agua es particularmente crítica, puesto que hay una amplia zona en que el recurso se declaró agotado y otras en que hay restricción de su uso. Y pese a esta escasez de agua, se pronostica que a futuro la industria del cobre seguirá creciendo, aumentando el consumo de este recurso por la expansión de los proyectos existentes y/o el desarrollo de otros nuevos, quienes desgastarán los yacimientos, explotando los de baja ley (ante el déficit de yacimientos de alta ley) para obtener cobre fino, los cuales requieren de mayores cantidades de agua ( $\mathrm{Mi}-$ nera Escondida 2008, 2013; COCHILCO 2012, 2013a).

En pocas palabras, al hablar de MEL estamos hablando de una empresa perteneciente a la categoría de "gran minería" y de un gigante internacional. El agua para esta empresa es un insumo importantísimo en su producción de cobre, indispensable y urgente, y por ende, el discurso sociedad. Nuestro objetivo es permanecer en la Región de Antofagasta por mucho tiempo más, de manera que continuaremos apoyando activamente iniciativas que mejoren la calidad de vida de los habitantes de Antofagasta y contribuyan al desarrollo del país" (Minera Escondida 2013: 5).

A continuación, se presenta una tabla (Tabla 2) que compara los números productivos de MEL entre el 2007 y 2012, de modo de comprender las grandes cifras de esta empresa privada.

\section{De la fricción al sistema interétnico}

En este apartado se evidencian las dinámicas de estas particulares relaciones interétnicas, a través de sus interacciones y conflictos. Podemos ver claramente que en el caso de Pampa Colorada se produce una fricción interétnica a causa del agua subterránea emplazada en territorio atacameño. En este contexto, las comunidades atacameñas de Socaire, Peine, Toconao y San Pedro, sin olvidarnos del Consejo de Pueblos Atacameños, se organizan como grupo social, buscando todos sus elementos

Tabla 2. Comparación de los datos operacionales de MEL de los años 2007 y 2012.

\begin{tabular}{|c|c|c|}
\hline Datos operacionales de MEL & $\mathbf{2 0 0 7}$ & $\mathbf{2 0 1 2}$ \\
\hline Producción mundial de cobre & $9,26 \%$ & $6,3 \%$ \\
\hline Producción & $1.483 .934 \mathrm{t}$ & $1.075 .825 \mathrm{t}$ \\
\hline Ventas & US $\$ 10.119$ millones & US $\$ 8.824$ millones \\
\hline Valor Económico Distribuido & US $\$ 8.976$ millones & US $\$ 5.917$ millones \\
\hline Utilidades & US $\$ 6.466$ millones $\$ 3.167,9$ millones \\
\hline Impuestos al Estado & US $\$ 2.786$ millones & US $\$ .169$ millones \\
\hline Inversión en Medioambiente & US $\$ 6$ millones & US $\$ 8$ millones \\
\hline Inversión en Comunidad & US $\$ 18$ millones & 67 millones \\
\hline Consumo de agua & $95.796 .023 \mathrm{~m}^{3}$ & 4.103 \\
\hline Dotación propia de trabajadores & $3.09999 \mathrm{~m}^{3}$ \\
\hline Contratistas operacionales & 4.398 & 11.830 \\
\hline
\end{tabular}

de la minera es eminentemente desarrollista. En resumen, esta empresa privada afirma: el mundo necesita cobre, casi todas las industrias lo necesitan y MEL lo produce. Al hacerlo, contribuye al progreso de la sociedad y, por lo tanto, al mejoramiento de la calidad de vida y la disminución de la pobreza (Minera Escondida 2013). En el último Reporte de Sustentabilidad publicado por la empresa se dice, por ejemplo:

"Operamos uno de los mayores yacimientos del mundo, por lo que nuestra presencia e impacto económico son significativos, como lo son también nuestra responsabilidad y nuestro rol en la comunes identitarios con fines de organización social para enfrentarse a un poderoso de la industria cuprífera mundial y al Estado. De inmediato se genera una identidad contrastante, en que se puede distinguir un nosotros frente a un otro, emergiendo la fricción interétnica a causa de, precisamente, un contacto interétnico, en que hay intereses opuestos sobre un mismo recurso, el agua. Vale decir, lo que se genera aquí es un sistema interétnico del tercer tipo, que define Cardoso de Oliveira como de relaciones de sujeción y dominación de índole asimétrica, a causa de los diferentes usos y valoraciones del recurso hídrico. 
En este sistema interétnico asimétrico con relaciones de sujeción y dominación, los actores en juego son las comunidades atacameñas y la sociedad global, representada por medio de los empresarios de Minera Escondida y el personal estatal ${ }^{15}$. Emerge una fricción interétnica a causa de un contexto de neocolonialismo, pues los empresarios de la sociedad global se quieren apropiar de los recursos naturales de los indígenas que, para este caso, hablaríamos del recurso más vital de todos, el agua. Esto lo pueden hacer los empresarios a causa de su poderío económico, técnico y jurídico. En un contexto interétnico como éste, las identidades étnicas emergen naturalmente con fines de organización, y de autoadscripción y adscripción de los otros, es decir, como una identidad contrastante. Para el caso de las comunidades atacameñas, ellas se reconocen como tales y sobre todo a través del Consejo de Pueblos Atacameños, lo que les da su calidad étnica.

Hay intereses económicos contradictorios entre ambas facciones, pues las comunidades atacameñas quieren mejorar su calidad de vida pero no a cambio de un precio tan alto como lo es la cesión del agua, cuya escasez podría generar el desplazamiento definitivo de estas comunidades de sus lugares de origen y la pérdida de su modo de vida, el cual se basa en actividades agropastoriles, artesanía y el turismo, bajo el amparo de los cerros tutelares y el agua, quienes en conjunto enlazan toda una organización social y política atacameña. Por su parte, los empresarios querían adueñarse del territorio indígena teniendo como visión sus recursos, de modo tal de aumentar su proceso productivo y hacer más rentable el negocio minero. Ahora bien, no podemos negar que los indígenas atacameños dependen de los bienes que

15 Nosotros, en términos analíticos, identificamos tres actores: comunidades indígenas, empresas privadas y agencias estatales, pero no podemos levantar estas categorías de forma aislada o de manera impermeable, sino todo lo contrario, pues ellas se erigen porque precisamente están en un contacto permanente unas con otras. Es decir, hay una interacción continua entre estos actores, sus fronteras son permeables $y$, hasta en ocasiones, difusas, pues puede suceder perfectamente que miembros de estos tres sectores puedan cambiar de bando a lo largo de su trayectoria política y/o laboral. No obstante, para el caso de Pampa Colorada, estos tres sectores funcionan internamente homogéneos (a través de las alianzas políticas de las comunidades, por ejemplo) y externamente diferentes, lo que nos da grandes ventajas analíticas. le otorga la sociedad nacional, pues cada vez están más insertos en las lógicas globales, lo cual se ha debido a la expansión de la misma sociedad nacional y global, quien ya parece haber agotado sus recursos en sus territorios, dirigiéndose a los de estas comunidades ancestrales, que han sabido mantener un equilibrio con la naturaleza por medio de siglos, lejos del paradigma desarrollista y la sobreexplotación de sus recursos, estableciendo otra relación con el medioambiente.

A pesar de haber sido olvidados por décadas, las comunidades atacameñas hoy están en los planes de desarrollo y expansión de la sociedad global, pues tanto su mano de obra como sus territorios han sido valorizados, como diría Cardoso de Oliveira, y sobre todo en Pampa Colorada a causa de la presencia de fuentes de agua dulce, que podrían abaratar los costos de los procesos productivos mineros y expandir la industria cuprífera no solo nacional, sino mundial.

Desde el Consejo de Pueblos Atacameños hay completa conciencia de la relación que establece el pueblo Lickanantai con empresas privadas y el Estado, así como de las consecuencias negativas que ha tenido para su cultura y así lo expresan: "Desde ya nos aventuramos a identificar al contacto entre culturas (la Atacameña con la Chilena o la Extranjera) como algo que puede tener importantes consecuencias aculturizadoras y económicamente negativas para el pueblo Likan Antai, debido a la forma en que se introduce una cultura externa y su modelo económico desestructurando nuestra estructura social indígena" (II Congreso Atacameño 2008: 9).

Bajo estas premisas, los pueblos indígenas quedan doblemente subyugados, pues por un lado, viven una sujeción étnica, con todas las implicancias de la fricción interétnica, y por otro, una sujeción interregional, en que una región subdesarrollada queda sometida a una desarrollada, de la cual emigran capitales, organizaciones empresariales y, muchas veces, las decisiones sobre el destino de las poblaciones locales, indígenas o no, son tomadas desde las zonas desarrolladas hacia las subdesarrolladas. Así pasó en Pampa Colorada, hacia donde emigraron los capitales de MEL y donde las decisiones sobre el destino de las poblaciones locales fueron tomadas en la COREMA de Antofagasta, es decir, desde una zona desarrollada hacia una subdesarrollada. 
De cualquier modo, las comunidades atacameñas se organizaron políticamente y finalmente no fueron subyugadas, lograron defender el agua, pero no tan solo este recurso, sino que también su territorio y modo de vida cultural.

\section{De la identidad común al movimiento social}

El esquema de Cardoso de Oliveira no solo sirve para analizar el caso del conflicto de Pampa Colorada, sino que también la constitución del Movimiento Indígena Atacameño, que logró frenar el proyecto de Escondida. Esto debido a que, antes de la Ley Indígena (1993) y del Consejo de Pueblos Atacameños, las localidades del salar de Atacama (como San Pedro y Toconao) habían discriminado históricamente a las de la Puna (como Socaire, Peine, Camar y Talabre), denominándoles "collas" (entre otros) y atribuyéndoles costumbres denigrantes (Morales 2013), lo cual está directamente asociado a los diferentes modos de vida que tenían ambas poblaciones; los primeros eran agricultores, e históricamente han estado más vinculados a los centros urbanos, mientras que los segundos eran pastores y vivían desperdigados en la precordillera. O sea, se trataría de un sistema intertribal asimétrico con relaciones jerárquicas, en que un grupo de indígenas se posiciona étnicamente por sobre otro. Antes de continuar haremos una salvedad, pues el concepto intertribal no aplica para las comunidades atacameñas, pues su constitución social y política, como en todo el mundo andino, no se da por tribus, por lo que nosotros hablaremos de un sistema entre comunidades indígenas asimétrico con relaciones jerárquicas.

Por lo demás, antes de la ley, las ahora comunidades indígenas atacameñas no se autorreconocían como tales, sino como pueblos rurales del interior de Calama. Es solo en este proceso de formación de la Ley Indígena que estas comunidades son reconocidas en su calidad étnica por el Estado, lo que paralelamente las hace autorreconocerse, es decir, se da el proceso de etnogénesis.

Bajo esta perspectiva se puede afirmar que por medio del reconocimiento étnico de la Ley Indígena y del Consejo de Pueblos Atacameños, las diferencias se han podido silenciar en cierto grado (no podemos afirmar que hayan desaparecido) entre las comunidades del salar y las de la puna. En este sentido, se comienza a adquirir una identidad común, la que al pasar de los años, y tras varios hitos, ha ido conformando un Movimiento Social Atacameño unificado que logre obtener réditos políticos, económicos, sociales y culturales, ante lo cual fue estrictamente necesaria la unificación étnica de las diferentes comunidades, así como su autoadscripción étnica, es decir, la generación de una identidad común. Si tal cuestión no hubiese sucedido, hubiese sido imposible un Consejo de Pueblos Atacameños y a las comunidades de Socaire, Peine, Toconao y San Pedro de Atacama actuando unidas en contra de las pretensiones de Minera Escondida y de la sociedad nacional en general ${ }^{16}$.

Es necesario destacar que la identidad colectiva es parte fundamental de un movimiento social, pero no es lo único, debe ir acompañado de una red informal compuesta por individuos, grupos $y / u$ organizaciones (comunidades y asociaciones indígenas, individualidades políticas y el Consejo de Pueblos Atacameños); antagonismos por el control de recursos (aguas, tierras, recursos naturales, medioambiente y patrimonio, disputas que se dan entre privados, Estado y atacameños); el uso de la protesta (marchas, declaraciones públicas, banderas negras, mensajes radiales, ante situaciones que no le han parecido viables al pueblo atacameño o ante sus propias demandas); y una perduración en el tiempo (desde comienzos de la década de 1990 hasta la actualidad, cuestión que se puede detectar a lo largo de los sucesivos congresos en que el pueblo discute y levanta sus demandas).

\section{REFLEXIONES FINALES}

Si bien el cobre abunda en el norte de Chile, las fuentes de agua son escasas, lo que dificulta la explotación minera de tal recurso por parte de empresas privadas, cuestión que en la actualidad se ve aún más compleja frente al nivel de organización social de las comunidades atacameñas, quienes cada día más quieren ser parte

16 Si no hubiese habido un reconocimiento étnico atacameño, quizás igualmente hubiese habido un movimiento ciudadano en contra de este tipo de proyecto minero, pero quizás se hubiese actuado de forma más desintegrada y sin un componente fundamental, el étnico, el cual tiene mayor resguardo en la legislación nacional e internacional. 
de las decisiones económicas que se toman sobre sus territorios, lo que hace que estos conflictos adquieran una gran complejidad social.

Nuestra hipótesis se verifica al documentar que los conflictos entre comunidades indígenas y minería emergen de las fricciones y relaciones sociales interétnicas en contextos neoliberales y multiculturales. Lo que se propone en este artículo es comenzar a ver esta clase de conflictos culturales como sistemas interétnicos. En un caso insigne de San Pedro de Atacama, como lo es Pampa Colorada, se da una situación interétnica en que se enfrentan las comunidades atacameñas con la empresa transnacional MEL y el Estado. En este contexto, las comunidades atacameñas se organizan como cultura buscando todos sus elementos comunes identitarios con fines de organización social para enfrentarse a un poderoso de la industria cuprífera mundial y al Estado. De inmediato se genera una identidad contrastante en que se puede distinguir un nosotros frente a un otro, emergiendo la fricción interétnica a causa de, precisamente, un contacto interétnico, en que hay intereses opuestos sobre un mismo recurso, el agua, el cual tiene diferentes usos y valoraciones para ambas culturas. Tales niveles de organización política se han ido desarrollando desde comienzos de la década de 1990, en donde se logran superar las fricciones intraétnicas a través del proceso de gestación de la Ley Indígena hasta llegar a la etnogénesis del pueblo atacameño y su identidad colectiva, cuyo gran representante hoy es el Consejo de Pueblos Atacameños.
Es así que en Pampa Colorada, y en esta clase de conflictos entre comunidades indígenas y minería, emerge la fricción interétnica a causa de un contexto de colonialismo en el cual los empresarios de la sociedad global se quieren apropiar de los recursos naturales de los indígenas; para este caso, hablaríamos del recurso más vital de todos en un desierto, el agua. Esto lo pueden hacer los empresarios a causa de su poderío económico, técnico y jurídico.

Recapitulando, proponemos que:

Solo la superación de las rivalidades intraétnicas del pueblo atacameño, y la constitución de una identidad colectiva, les permitió a estas comunidades indígenas enfrentarse ahora en un sistema interétnico a las empresas mineras sobre una base política más sólida, en forma de movimiento social, y salir finalmente victoriosas.

De esta manera, la etnicidad en contextos de conflicto intercultural puede ser entendida como una relación social que ocurre en un contexto particular, circunstancial y contingente. También se erige socialmente en espacios de frontera cultural, permitiendo visibilizar la emergencia de sujetos, escenarios y relaciones sociales que configuran procesos etnopolíticos de diferenciación cultural. Si bien ocupamos el concepto de sistema interétnico en un conflicto por el agua en Atacama, bien puede suceder en otra clase de conflictos en la zona, como el turismo o el patrimonio.

\section{* Referencias citadas}

ANDERSON, B. 1993. Comunidades Imaginadas: reflexiones sobre elorigen y la difusión del nacionalismo, (2 ${ }^{\mathrm{a}}$ edición). Fondo de Cultura Económica, México, D.F.

AZÓCAR, R. 2015. Pampa Colorada: conflicto etno-ambiental y Movimiento Indígena Atacameño. Memoria para optar al Título de Antropólogo Social en la Facultad de Ciencias Sociales de la Universidad de Chile, Santiago de Chile.

BARROS, A. 2008. Agua subterránea: derechos colectivos, autonomía, mercado y justicia ambiental en el territorio Lickanantay (Desierto de Atacama, Chile). En Globalización, Derechos Humanos y Pueblos Indígenas, Á. Bell y J. Aylwin (Comps.), pp. 347-372. Observatorio de Derechos de los Pueblos Indígenas, Temuco.

BARTH, F. 1976. Los grupos étnicos y sus fronteras. Fondo de Cultura Económica. México, D.F.

BERGER, P. y T. LUCKMAN. 1973. La construcción social de la realidad. Amorrortu Editores, Buenos Aires.

BOELENS, R. 2011. Luchas y defensas escondidas. Pluralismo legal y cultural como una práctica de resistencia creativa en la gestión local del agua en los Andes. Anuario de Estudios Americanos 68 (2): 673-703.

BOLADOS, P. 2014. Los conflictos etnoambientales de "Pampa Colorada" y "El Tatio" en el Salar de Atacama, norte de Chile. Procesos étnicos en un contexto minero y turístico transnacional. Estudios Atacameños 48: 229-248. 
CARDOSO DE OLIVEIRA, R. 2007. Etnicidad y estructura social. Clásicos y Contemporáneos en Antropología, México D.F.

CASTRO, M., M. BAHAMONDES, M. GOIO, y C. MENESES. 1990. Componentes culturales en la gestión de recursos hídricos. Un estudio local: Chile. Unesco, Santiago de Chile.

CASTRO, V., V. VARELA, L. ADÁN, C. MERCADO y M. URIBE. 1994. Ceremonias de tierra y agua. Ritos milenarios andinos. Kuppenheim y Cía, Santiago de Chile.

COCHILCO. 2012. Consumo de agua en la minería del cobre 2011. Comisión Chilena del Cobre. Dirección de Estudios y Políticas Públicas, Santiago de Chile.

2013a. Actualización de la información sobre el consumo de agua en la minería del cobre al año 2012. Comisión Chilena del Cobre. Dirección de Estudios, Santiago de Chile.

2013b. Anuario de estadísticas del cobre y otros minerales 1993-2012. Editora e Imprenta Maval, Santiago de Chile.

COHEN, A. 1974. Introduction: The Lesson of Ethnicity. En Urban Ethnicity. ASAl. Tavistock Publications, Londres.

COREMA DE ANTOFAGASTA. 2007. Resolución Exenta $N^{\circ}$ 366/2007. Gobierno de Chile, Comisión Regional del Medio Ambiente, Región de Antofagasta, Antofagasta.

DE VOS, G. y L. ROMANUCCI-ROSSI. 1982. Ethnic Identity. University of Chicago Press, Chicago.

DIRECCIÓN GENERAL DE AGUAS (DGA). 2000. Declara el agotamiento del Río Loa y sus afluentes, II Región. República de Chile, Ministerio de Obras Públicas, Dirección General de Aguas, Departamento de Administración de Recursos Hídricos, Región de Antofagasta, Antofagasta.

FOLCHI, M. 2003. La insustentabilidad del boom minero chileno: política y medioambiente, 1983-2003. Ecología Política 26:23-50.

2009. Política, ambiente y la insustentabilidad de la minería en Chile. En Extractivismo, politica y sociedad, J. Schuldt, A. Acosta, A. Barandiarán, A. Bebbington, M. Folchi, CEDLA-Bolivia y otros, pp. 79-106. Centro Andino de Acción Popular (CAAP), Centro Latinoamericano de Ecología Social (CLAES) y Rosa Luxemburgo Stiftung de Alemania, Quito.

GENTES, I. 2004. Estudio sobre marcos normativos indígenas y consuetudinarios del derecho al agua en Chile. CEPAL. En línea, disponible en: http://www.eclac.cl/drni/proyectos/walir/doc/walir31.pdf (recuperado el 17 de julio de 2013).
GLAZER, N. y D. MOYNIHAN. 1975. Ethnicity: Theory and Experience. Harvard University Press. Cambridge, Massachusetts.

HOBSBAWM, E. 2002 [1983]. La Invención de la Tradición, E. Hobsbawm y T. Ranger (Eds.), pp. 7-21. Editorial Crítica, Barcelona.

ISAACS, H. 1975. Idols of the Tribe, Group Identity and Political.Change. Harper \& Row Publishers, New York.

I CONGRESO ATACAMEÑO. 1998. Ia ckari latckitur nisaya sema lickana. El nuevo amanecer de un pueblo. Comunidad de Chiu-Chiu.

II CONGRESO ATACAMEÑO. 2008. Laycku ckotch heutur nisayá Lickan-Antay. Por la autodeterminación del pueblo atacameño. Comunidad de Toconao.

LARRAÍN, S., P. POO y P. C. SUSTENTABLE. 2010. Pampa Colorada: intento de mayor extracción de aguas por Minera Escondida. En Conflictos por el agua en Chile. Entre los Derechos Humanosy las reglas del mercado, S. Larraín, P. Poo y P. C. Sustentable (Eds.), pp. 119-127. Gráfica Andes, Santiago de Chile.

LA TERCERA. Escondida desarrollará planta desalinizadora por US\$3.430 millones para asegurar suministro de agua. La Tercera (25 de julio 2013).

MADALENO, I. 2009. El derecho de los pueblos indígenas a resistir al derecho-manejo del agua en el norte de Chile. Revista Latinoamericana de Desarrollo Económico 11: 1-27.

MC PHEE, B. 2010. Conflictos ambientales y respuestas sociales: el caso de reetnificación de la comunidad de Quillagua. Revista Mad 22: 42-55.

MINERA ESCONDIDA. 2008. Reporte de Sustentabilidad 2007. Quebecor World Chile S.A., Antofagasta. 2013. Informe de Sustentabilidad 2012. Ograma, Antofagasta.

MOLINA, R. 2006. El río Loa: usos y conflictos por el agua en el Desierto de Atacama. Comunidades indígenas, mineras, ciudades y pueblos. Dirección General de Aguas (DGA). En: http://www.infoandina. org/es/content/el-rio-loa-usos-y-conflictos-por-el-agua-en-eldesierto-de-atacama-comunidades-\% C3\%ADndigenas

2007. Comunidades atacameñas y empresas mineras: contacto cercano entre identidad étnica y globalización. Programa de Doctorado en Antropología (2006-2010) de la Universidad de Tarapacá. Universidad de Tarapacá, Arica.

MORALES, H. 2010. Etnopolítica en Atacama. Laberintos de etnicidad atacameña en Chile. Tesis doctoral en la Universidad Libre de Berlín, Berlín. 
2013. Construcción social de la etnicidad. Ego y alter en Atacama. Estudios Atacameños 46: 145-164.

2014. Génesis, formación y desarrollo del movimiento atacameño (norte de Chile). Estudios Atacameños 49: 111-128.

MOSTNY, G. 1954. Peine, un pueblo atacameño. Instituto de Geografía, Facultad de Filosofía, Universidad de Chile, Santiago de Chile.

RIVERA, F. 2005-2006. Entorno neoliberal y la alteridad étnica anti-flexible de los atacameños contemporáneos. Revista de Antropología 18: 59-89.

ROOSENS, E. 1989. Creating Ethnicity. The Process of Ethnogenesis. Sage Publications, Newbury Park, California.

SHILS, W. 1957. Primordial, personal, sacred and civil ties. British Journal of Sociology 8: 130-147.
SKEWES, J. C., R. REHBEIN y C. MANCILLA. 2012. Ciudadanía y sustentabilidad ambiental en la ciudad: la recuperación del humedal Angachilla y la organización local en la Villa Claro de Luna, Valdivia, Chile. EURE (Santiago) 38 (113): 127-145. En línea, disponible en: http://dx.doi.org/10.4067/So25071612012000100006 .

VALENZUELA, A. 2006. Atacameños de Calama. Diversidad, transitoriedad y fragmentación en las organizaciones atacameñas urbanas y su relación con el Estado chileno. Tesis de Maestría en CIESAS, Guadalajara.

YÁÑEZ, N. y R. MOLINA. 2008. La gran minería y los derechos indígenas en el norte de Chile. LOM Ediciones, Santiago de Chile.

2011. Las aguas indígenas en Chile. LOM Ediciones, Santiago de Chile. 